\title{
Speech and Thought Representation in Hemingway: The Case of Free Indirect Discourse
}

\author{
Olga A. Blinova \\ PhD student, MGIMO-University, Moscow, Russia \\ Email: blinova.o@gmail.com
}

\section{Doi:10.5901/mjss.2015.v6n1s1p458}

\section{Abstract}

The paper looks into modes of speech and thought presentation, with a particular interest in Free Indirect Discourse. Taking a functional perspective on Free Indirect Discourse, the research studies its formal and stylistic features in E. Hemingway's short stories. The aim of the study is to outline the factors that determine Hemingway's choice of this particular mode of discourse presentation. The discourse analysis of 37 samples of FID usage reveals a correlation between the formal features (deixis, tense usage, character speech markers) and stylistic functions of Free Indirect Discourse. These include either distancing the narrator from the character or virtually merging the two together.

Keywords: speech and thought presentation, discourse presentation, free indirect discourse, discourse analysis, narratology.

\section{Introduction}

Free Indirect Discourse is a stylistically marked mode of speech and thought presentation usually employed as a tool for blending the narrator's voice with that of the character's. This typically results in an ambiguity when determining the point of view. Although the point of view traditionally is by default assumed to belong to the speaker (the speaker being the narrator or a character when dealing with a dialogue), Free Indirect Discourse challenges the stereotype.

This article discusses the correlation of the formal and stylistic features of Free Indirect Discourse in Men without Women, a 1927 short story collection by Ernest Hemingway.

\section{Literature Review}

Modes of discourse (i.e. uttered speech and unuttered thought) representation have been studied within the framework of stylistics (Pascal 1977; Cohn 1978; Redeker, 1997; Blinova 2012), generative grammar (Banfield 1982), pragmatics (Fludernik 1993), discourse analysis (Halliday 1994), cognitive linguistics (Herman 1998), corpus linguistics (Wynne, Short and Semino 1998), and, most recently, formal semantics (Maier 2014). This paper explores how the functional features of Free Indirect Discourse are conditioned by its formal and contextual characteristics.

\subsection{Modes of discourse representation}

Leech and Short (1981) offered a system for speech and thought presentation which originally included five modes: Direct Speech/Thought (DS/DT), Indirect Speech/Thought (IS/IT), Free Direct Speech/Thought (FDT/FDT), Free Indirect Speech/Thought (FIS/FIT), and Narrative report of a Speech/Thought Act (NRSA). The difference between these modes lies on the formal level (their formal linguistic characteristics are different) as well as in their semantics. Later on, the system went on to incorporate more modes. For instance, Semino and Short (2004) proposes a mode labelled Narrative Report of Voice (NV). However, since NV does not feature an utterance as such, his study only focuses on the original five modes.

Originally called «speech and thought presentation», the system is more often referred to as «discourse presentation» to include analyses of both written and oral texts.

Leech and Short (1981) offer a cline that positions these modes according to the degree of control on the part of the character or the narrator: 
Table 1.

\begin{tabular}{|c|c|c|c|c|}
\hline \multicolumn{3}{|c|}{ Character apparently in control of speech act } & \multicolumn{3}{c|}{ Narrator apparently in control of speech act } \\
\hline FDD & DD & FID & ID & NRSA/NRTA \\
\hline \multicolumn{3}{|c|}{ Scale of Speech/Thought Representation } \\
\hline
\end{tabular}

As the reader's attention is gradually shifted to the right, the reader is drawn into the heads of a character, an effect that cannot be achieved by the use of more straightforward modes.

Tracing one speech act through all the five modes of representation helps describe their features. For example, a Narrative Report of a Speech Act (NRSA) such as «He didn't know whether she loved him» can be represented in a text in the following ways.

Direct Discourse (DD), be it speech or thought, also called quotation, reproduces the original words verbatim. The tense forms, deictic references, and original lexis are preserved as they have been uttered by the speaker.

e.g. «Does she love me?», he wondered.

Free Direct Discourse (FDD) is a variation where no inverted commas are used, and the utterance blends in with the narrative visually, but not formally. On the formal level it is identical to DD.

e.g. Does she love me? he wondered.

Indirect Discourse (ID), or reported speech/thought, is typically realized as the complement of a speech/thought verb (or its alternatives, e.g. phrases like «according to» etc.) and represents the utterance form the current, not original, speaker's perspective. Formally ID is characterized by a tense shift, a deictic shift, and a less literal reproduction of the original wording.

e.g. He wondered if she loved him.

The interrogative sentence is changed to an affirmative clause which is introduced by a speech verb and takes the form of its complement.

Free Indirect Discourse (FID), which will be looked at in detail further, is essentially a mixture of DD and ID. It preserves the features of both DD (the sentence is still interrogative and is not a dependent clause even if the speech verb is preserved) and ID (the tense forms and pronouns shift to the ID model).

e.g. Did she love him? (he wondered).

Fludernik (1993) argues that «a study on free indirect discourse alone would be patently pointless. Taken on its own, it is an elusive phenomenon which has neither a necessary nor a sufficient formal characteristic. All things being equal (which, of course, they rarely are), Oh, she simply hated her daughter! can as easily be a sentence of narrative report as She was tired can be a piece of free indirect discourse (...) As a "reportative" or "quotational" device, it must also be seen against the background of and in its interaction with other types of speech and thought representation».

\subsection{Free Indirect Discourse}

Free Indirect Discourse (FID) is a separate mode of speech and/or thought representation. It is argued to have appeared as early as in Ancient Greek, although recent research has sought to disprove the claim (Maier 2014). In English language fiction FID is first recorded in Chaucer's Canterbury Tales. However, it was not until Jane Austen's work that FID turned into a full fledged technique to be used widely by English authors. Traditionally associated with fiction texts, FID has been shown to be used in a variety of genres, including journalism (Blinova 2012).

Other terms used to denote this technique include «narrated monologue» and «represented speech». However, today the consensus is to term it «Free Indirect Discourse», which is based on the original French term, coined by Ch. Bally in 1912, style indirect libre (Bally 1912). This article uses the term «Free Indirect Discourse», or FID, to refer to both Free Indirect Speech and Free Indirect Thought where a distinction between the two is not required. However, it should be borne in mind that some scholars consider the term FID to refer primarily to a mode of thought representation. For instance, Bray (2007) defines FID as «a narrative technique which purports to convey a character's mental language while maintaining third-person reference and past tense» (Bray J. 2007). 


\subsubsection{The Formal Perspective}

FID is characterized by the so-called shifts in the tense forms of the verbs, the personal pronouns, and deictic elements (spatial, demonstrative, etc). None of the shifts are obligatory, and some are in fact often disregarded by authors. This has led Fludernik (1993) to claim that all shifts except the personal pronominal are non-defining features of FID. The defining features include the aforementioned pronominal shift and absence of subordination (which distinguishes FID from ID).

Thus, in the following sentence from Hemingway, we observe:

Well, somebody would have to kill his other bull. They had cut away his shirt (...) To hell with this operating-table. He'd been on plenty of operating-tables before. (Hemingway 2004)

Temporal shifts from present to past are found in all the verbs, so are the pronominal shifts (from the first to the third person in possessive pronouns):

Table 2.

\begin{tabular}{|c|c|c|c|c|c|c|c|}
\hline DD & \multirow{2}{*}{ - } & \multirow{2}{*}{ Well, } & \multirow{3}{*}{ somebody } & will & \multirow{3}{*}{ have to kill } & my & \multirow{3}{*}{ bull. } \\
\hline FID & & & & \multirow{2}{*}{ would } & & \multirow{2}{*}{ his } & \\
\hline ID & he thought that & - & & & & & \\
\hline
\end{tabular}

The spatial deictic element in the next sentence, however, remains intact (ID would have required a shift: this operatingtable $\rightarrow$ that operating-table).

Banfield (1982) explains the shifts through a theory of two contexts. The Context of Thought refers to the point at which the thought originated, and all indexicals (demonstratives, spatial deixis, etc) are aligned depending on this context. The Context of Utterance, on the other hand, refers to the point when the thought is articulated. This is the context that defines the verb tense forms and personal pronouns, which is why they always shift in FID.

\subsubsection{The Stylistic Perspective}

Formal characteristics alone do not answer the fundamental question of why do authors choose a certain mode of speech representation. Concentrating on forms alone will inevitably lead to a loss of the complexity of modes of speech representation.

As a frequent device in fiction, FID is employed mainly as a means of characterization, portraying a person's thoughts or speech. It makes the text subjective and evaluative, acting as a means of revealing the author's or the narrator's attitude to the character described. As such, it can lead to two opposite effects, either resulting in sympathy (if the narrator's voice merges with the character's) or, on the contrary, irony (if the character's and the narrator's voices are opposed to each other). Similarly, FID provokes two opposite feelings from the readers, either in favour or against the character.

An account of FID use in a work of fiction is thus to be based on two angles. On the one hand, FID presents a number of formal characteristics, such as tense shifts, deictic shifts, or inclusion of character discourse markers. On the other hand, FID is recognized as a stylistic device that performs a certain function in the text. Thus, our analysis will look into both formal and functional features of FID in the three short stories.

\section{Analysis}

Free Indirect Discourse is found in three of the fourteen short stories that make up the collection, namely: A Banal Story, A Canary for One, and The Undefeated. The plots, settings, and atmosphere differ greatly; however, the speech and/or thought representation in these three pieces is built around the same mode. 


\subsection{Research methodology and objectives}

The functional characteristics will be analyzed in their dependence on the context in which FID appears in each case. The structure of the formal analysis is based on the core FID features:

- Presence/no index of personal deixis shift: $P_{1} / P_{x}$. The criterion describes not whether first-person reference is changed to third (to shift a personal pronoun if one is found in the sentence it is a defining feature of FID) but whether the sentence has a pronominal element.

- Presence/absence/no index of deixis shift: $\mathrm{S}_{1} / \mathrm{S}_{0} / \mathrm{S}_{\mathrm{x}}$. This parameter addresses the spatial shift (the change of space markers e.g. here -> there) as well as adverb indicators of time that help locate the action (e.g. now -> then) and demonstratives (this/that etc).

- Presence/absence/no index of temporal shift: $T_{1} / T_{0} / T_{x}$. This characteristic shows the shift from the present tense context to the past (e.g. would like $>>$ would have liked).

- Presence/absence of comment clause: $\mathrm{C}_{1} / \mathrm{C}_{0}$. Since certain scholars accept that, although rarely, FID still can feature the author's comment clause, this criterion is set to unveil the cases where the comment clause is present.

- Type of Sentence: A "affirmative/negative", E "exclamatory", or I "interrogative". FID operates the whole range of sentence types, and by means of this parameter the frequency of this or that type will be measured. It is important to note whether the sentence is exclamatory or interrogative as these two types are impossible in ID.

- Character discourse markers: $D_{1} / D_{0}$. The use of lexical units typical of the character whose speech is represented, as well as resort to structures proper to spoken discourse, is the common feature of FID and DD. The units are registered by this criterion.

The research objective is to build up statistics and reveal the frequency of the FID patterns used in Hemingway's short stories.

\subsection{Findings and discussion}

\subsection{1 "A Canary for One"}

In "A Canary for One" the story occurs in the early 1920s on a train headed toward Paris. The three characters, an older wealthy woman and a couple in their late twenties, are all Americans. The title of the story, brought about by the gift the lady is carrying to her daughter (a bird in a cage), has a symbolic meaning: the woman actually puts her daughter in a cage by interfering in her life. As they sit together on the train, the older woman initiates and then dominates the conversation. She tells the couple a story of her daughter's love affair with a Swiss which was abruptly cut off by the mother as, according to her principles "no foreigner can make an American girl a good husband". This is an idea she constantly returns to, repeating now and then, "I couldn't have her marrying a foreigner" or "American men make the best husbands". Learning that the younger woman's husband, who is actually the narrator of the story, is also an American, the older lady approves of their family. It is the revelation, present in the closing phrase, that the young couple are about to end their marriage that comprises the final irony of the story.

To show the narrator's contempt as far as the woman and her ideas go, Hemingway introduces the following passage, written entirely in FID:

"The American lady admired my wife's traveling-coat, and (1) $P_{1} S_{x} T_{1} C_{0} A D_{1}$ it turned out that the American lady had bought her own clothes for twenty years now from the same maison de couture in the rue Saint Honoré. (2) $P_{1} S_{x} T_{1} C_{0} A D_{1}$ They had her measurements, and a vendeuse who knew her and her tastes picked the dresses out for her and they were sent to America. (3) $P_{1} S_{x} T_{1} C_{0} A D_{1}$ They came to the post-office near where she lived up-town in New York, and the duty was never exorbitant because they opened the dresses there in the post-office to appraise them and they were always very simple-looking and with no gold lace or ornaments that would make the dresses look expensive. (4) $P_{x} S_{x} T_{1} C_{0} A D_{1}$ Before the present vendeuse, named Thérèse, there had been another vendeuse, named Amélie. (5) $P_{x} S_{0} T_{1} C_{0} A D_{x}$ Altogether there had only been these two in the twenty years. (6) $P_{x} S_{x} T_{1} C_{0} A D_{1}$ It had always been the same couturier. (7) $P_{x} S_{x} T_{1} C_{0} A D_{x}$ Prices, however, had gone up. (8) $P_{x} S_{x} T_{1} C_{0} A D_{x}$ The exchange, however, equalized that. (9) $P_{1} S_{x} T_{1} C_{0} A D_{0}$ They had her daughter's measurements now too. (10) $P_{x} S_{x} T_{1} C_{0} A D_{x}$ She was grown up and there was no chance of their changing now". (Hemingway; 2004).

On the one hand, there are elements of Indirect Speech, which only inform us of what the older woman was talking about ("The American lady admired my wife's traveling-coat" and the pronouns "her" in relation to the Lady's daughter.). 
On the other hand, Hemingway preserves a number of lexical elements, originally articulated by the American lady, that acquire an additional meaning now that they might potentially belong to the young man (the French words $D_{1}$-vendeuse and $\mathrm{D}_{1}$-maison de couture or the last phrase that could hardly be pronounced by a man). The constant repetition of some words (vendeuse, dresses, measurements etc) not only stresses the supposed emptiness of the Lady's preoccupations, but also serves as a means of sarcasm. This "chattering" annoys the young man, as he already has shaped his opinion about the fellow-traveller as of a vain, empty tyrant who believes to possess the right to judge about other people's lives and meddle in their relations, which often leads to ruining their happiness, like in her daughter's case. Thus, FID is used to express the author's sarcasm and carries elements of mockery.

\subsection{2 "Banal Story"}

"Banal Story" actually comprises two stories which mirror each other.

The first story portrays Hemingway's vision of the inefficient, inadequate, shallow contemporary American culture without rituals other than those of entertainment. It features a young man reading a yellow press magazine and enjoying poor articles where the absence of depth and authenticity is combined with entertainment.

The protagonist's thoughts and impressions about the information he learns while reading the booklet are presented in the form of FID. Actually, the text unfolding before the reader matches the protagonist's mind. The reader is left with the character's spontaneous emotional reactions to what he is reading. Thus, the main function FID carries in "Banal Story" is creating the protagonist's psychological character. However, Hemingway again uses FID to produce sarcastic effect. First, he stresses the man's appreciation of outer comfort:

"Inside, the electric stove seemed to give no heat... he sat down upon the stove. (11) $P_{x} S_{x} T_{1} C_{0} E D_{x}$ How good it felt! (12)

$P_{x} S_{0} T_{1} C_{0} E D_{x}$ Here, at last, was life!" (Hemingway 2004)

The example is notable for the absence of spatial shift ( $\mathrm{S}_{0}$-here is preserved and not changed to there) and for being exclamatory.

When the reader has obviously already formed an opinion on the magazine read by the protagonist (which is clearly portrayed as full of cheap sensations about boxers, as well as mediocre and dilettantish art criticism; the booklet is totally devoid of any sense of coherence or profoundness), Hemingway inserts the FID phrase,

\section{(13) $P_{x} S_{x} T_{1} C_{0} A D_{1}$ "It was a splendid booklet". (Hemingway 2004)}

Here it serves the unusual purpose of distancing the author from his character, to add a sarcastic shade to the narration. The fact of resorting to the stylistic device of FID instead of a mere Indirect Speech underlines Hemingway's contempt and annoyance at his protagonist. The evaluator $\mathrm{D}_{1}$-splendid here functions as a character discourse marker and brings forth the clash between the objective assessment of the magazine and the character's attitude to it.

\subsection{3 "The Undefeated"}

"The Undefeated" is one of the stories inspired by E. Hemingway's passion for bull fighting. Its main character is an old bull fighter, Manuel, who strives to return to arena after a long period in hospital. However, his popularity with the public has faded and he has to fight his way back on the arena. The story is centered round two fights: a metaphorical one, where Manuel is trying to persuade the manager to let him perform; and a real fight, with Manuel killing a bull but getting badly hurt in the course of the fight. He ends up a loser of both battles, as he is in hospital again, and the public doesn't sympathize with him any more, but refuses to accept the defeat.

Hemingway always showed deep appreciation and awe for bull fighters, considering it a chance to demonstrate one's bravery and strength of character. Manuel is the only character in the story whose mind is open to the reader through the use of FID. It is used on several occasions.

The most prominent use is found in the description of Manuel's last fight. FID is an instant representation of Manuel's thoughts, and the reader gets them as soon as the character performs a certain action. The instantaneity is explained by the absence of comment clauses, since only the character's words are left in the text. FID speeds the pace of the narration bringing up the climax of the story:

(14) $P_{x} S_{1} T_{1} C_{0} A D_{0}$ There was the bull. (15) $P_{1} S_{0} T_{1} C_{0} A D_{1}$ He was close to the barrera now. (16) $P_{x} S_{x} T_{x} C_{0} A D_{1}$ Damn him.

(17) $P_{x} S_{x} T_{1} C_{0} A D_{x}$ Maybe he was all bone. (18) $P_{x} S_{x} T_{1} C_{0} A D_{0}$ Maybe there was not any place for the sword to go in. (19) 
$P_{x} S_{x} T_{1} C_{0} E D_{1}$ The hell there wasn't! (20) $P_{1} S_{x} T_{x} C_{0} A D_{x}$ He'd show them. (..) (21) $P_{x} S_{x} T_{x} C_{0} E D_{1}$ Oh, the dirty bastards! (22) $P_{x} S_{x} T_{x} C_{0} E D_{1}$ Dirty bastards! (23) $P_{x} S_{x} T_{x} C_{0} E D_{1}$ Oh, the lousy, dirty bastards! (24) $P_{x} S_{1} T_{1} C_{0} A D_{x}$ There was the bull.

(25) $P_{X} S_{X} T_{X} C_{0} E D_{1}$ All right, you lousy, dirty bastard! Manuel passed the muleta in front of the bull's black muzzle. (26) $P_{x} S_{x} T_{x} C_{0} A D_{1}$ Nothing doing. (27) $P_{x} S_{x} T_{0} C_{0} E D_{x}$ You won't! (28) $P_{x} S_{x} T_{x} C_{0} A D_{x}$ All right. (...) He must go over and salute the president. (29) $P_{x} S_{x} T_{x} C_{0} E D_{1}$ President hell! (Hemingway 2004)

The character's emotional state is vividly transmitted through the abundance of exclamatory sentences and by means of the expressive lexical units, which serve as character discourse markers; so does the Spanish word $\mathrm{D}_{1}$-barrera, used instead of barrier. The interjections are a feature of oral speech rather than a written text; the structure of some sentences suggests they are representation of oral utterances. Seeing the events with the character's eyes the reader lives through the fight. Thus, FID enhances the affecting potential of the story and its emotional power.

After the fight Manuel is taken to hospital, and his mind becomes foggy with fever. The reader can follow his chaotic thoughts, as Hemingway once again resorts to FID to render them.

(30) $P_{x} S_{1} T_{1} C_{0} A D_{x}$ That was the crowd. (31) $P_{1} S_{x} T_{1} C_{0} A D_{1}$ Well, somebody would have to kill his other bull. (32) $P_{1} S_{x} T_{1} C_{0} A D_{x}$ They had cut away his shirt (...) (33) $P_{x} S_{0} T_{x} C_{0} A D_{1}$ To hell with this operating-table. (34) $P_{1} S_{x} T_{1} C_{0} A D_{x} H e^{\prime} d$ been on plenty of operating-tables before. (35) $P_{1} S_{x} T_{1} C_{0} A D_{x}$ He was not going to die. (36) $P_{1} S_{x} T_{1} C_{0} A D_{x}$ There would be a priest if he was going to die (...) (37) $P_{x} S_{1} T_{1} C_{0} A D_{x}$ That was it. (Hemingway 2004)

FID is once again used seeking a bigger emotional impact on the reader. The language means are less expressive than in the first case since the character's state has changed greatly, as he has trouble understanding what is going on around him, he has lost concentration and his mind is drifting back to the memories of the past. There are neither exclamatory sentences nor emotionally coloured words. The passage is found after the climax, where the tension and suspense of the story have gone, and the general impression is rather of hopelessness than of energy and aggression (as in the first case). FID allows to immediately convey the change of the character's inner state.

\section{Concluding Remarks}

Statistically the cases of FID in early Hemingway demonstrate the following distribution of non-defining features (see Fig. 1).

Pronominal shifts are observed in $70 \%$ of cases, while the rest of the sentences carry no personal pronouns that can be shifted. Tense shift is observed in $70 \%$ of cases, with $27 \%$ of sentences having no verbal component, and one sentence (3\%) demonstrating no tense shift at all. The majority of examples (78\%) do not contain any space, temporal, or demonstrative indexicals. However, if present, they may or may not result in a shift with equal probability (11\%).

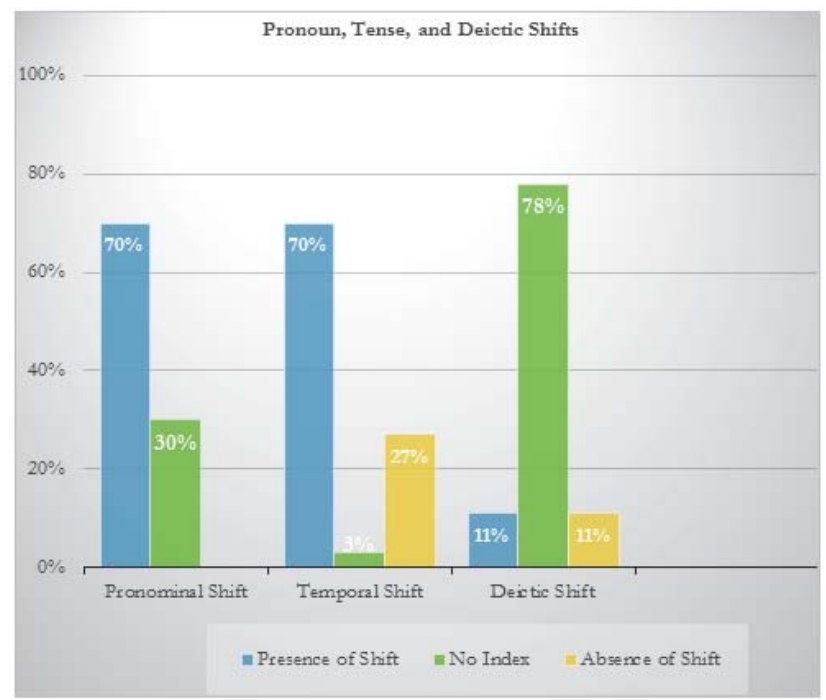

\section{Figure 1.}


In terms of sentence types, $76 \%$ of sentences are affirmative/negative, while $24 \%$ preserve the exclamation mark linking the FID examples to DD.

Character discourse markers are evenly distributed, with $54 \%$ of examples showing absence of discourse markers and $46 \%$ showing their presence (see Fig. 2).

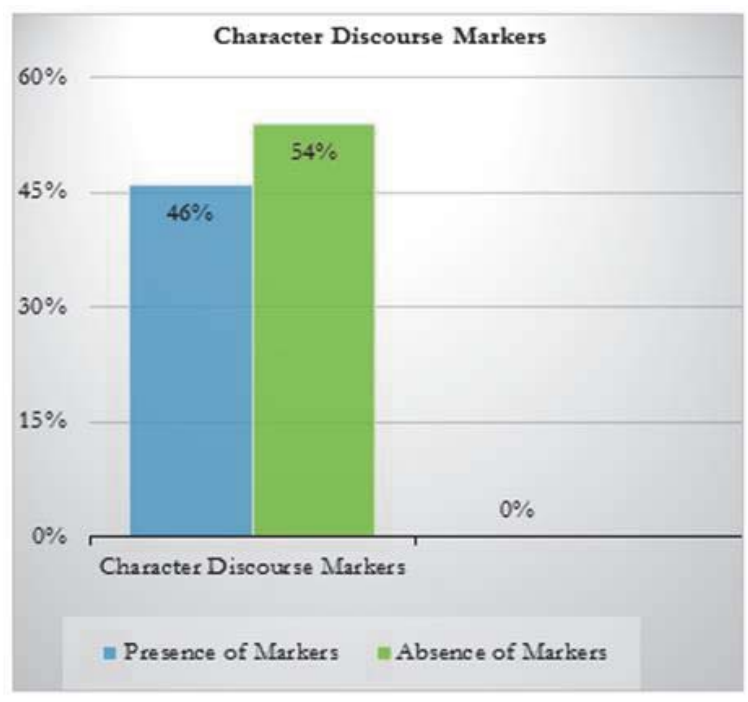

\section{Figure 2.}

Hemingway resorts to FID to various ends. The general function FID performs in all the short stories analyzed here is to give a character's emotional portrait. Nevertheless, in some stories FID carries a number of additional functions. For instance, in "A Canary For One" it is a means of irony. FID not only characterizes the older lady but also helps to convey the narrator's attitude towards her.

Although it is generally accepted that FID merges the author's voice with that of his character to show their solidarity with the latter, it can serve the opposite purpose. Thus, in "A Banal Story", Hemingway resorts to FID to show his contempt towards his protagonist, i.e. to distance himself from the character. FID here is not a fusion of voices but a means by which the author is basically shirking off responsibility for his character's speech.

\section{References}

Bally, Charles. (1912). Le style indirect libre en français moderne. GermanischRomanische Monatschrift. 4, 549-556.

Banfield, Anne. (1973). Narrative style and the grammar of direct and indirect speech. Foundations of Language, 10, 1-39.

Blinova, Olga. (2012). The notion of free indirect discourse and its use in contemporary fiction. Humanities and Human Sciences Review, 01(02), 365-371.

Bray, Joe. (2007). The "Dual Voice" of Free Indirect Discourse: A Reading Experiment. Language and Literature, 16 (1), $37-52$.

Cohn, Dorrit. (1978). Transparent minds: Narrative modes for presenting consciousness in fiction. (2nd ed.). Princeton NJ: Princeton University Press.

Fludernik, Monika. (1993). The fictions of language and the languages of fiction: The linguistic representation of speech and consciousness. London: Routledge.

Halliday, M. A. K. (1994). An introduction to functional grammar. London: Edward Arnold.

Hemingway, Ernest. (2004). Men Without Women. Arrow Books, London.

Herman, Vimala. (1998). Dramatic Discourse: Dialogue as Interaction in Plays. London \& New York: Routledge.

Leech, Geoffrey N., Short Michael H. (1981). Style in fiction. London: Longman.

Maier, Emar. (2014). Language Shifts in Free Indirect Discourse. Journal of Literary Semantics. 43(2), 143-167.

Pascal, Roy. (1977). The Dual Voice: Free Indirect Speech and Its Functioning in the Nineteenth-Century European Novel. Manchester: Manchester University Press.

Semino E., Short, Mick. (2004). Corpus Stylistics: Speech, Writing and Thought Presentation in a Corpus of English Writing. London.

Wynne, M, Short, M, Semino, E. (1998) A corpus-based investigation of speech, thought and writing presentation in English narrative texts. Renouf, A (ed), Explorations in Corpus Linguistics. Amsterdam, Rodopi, 231-245. 